\title{
The Relationship between Thrombolysis in Myocardial Infarction Frame Count and Fractional Flow Reserve in Patients with Moderate Coronary Stenosis Undergoing Coronary Angiography
}

\author{
Arash Gholoobi ${ }^{1, *}$, Mahmoud Mohammadzadeh Shabestari ${ }^{2}$, Ahmad Jamshid Rezaei ${ }^{3}$, Vahid \\ Reza Dabbagh $^{4}$ \\ ${ }^{I}$ Assistant Professor, Atherosclerosis Prevention Research Center, Mashhad University of Medical Sciences, Mashhad, Iran \\ ${ }^{2}$ Professor, Atherosclerosis Prevention Research Center, Mashhad University of Medical Sciences, Mashhad, Iran \\ ${ }^{3}$ Cardiologist \\ ${ }^{4}$ Associate Professor, Department of Nuclear Medicine, Faculty of Medicine, Mashhad University of Medical Sciences, \\ Mashhad, Iran \\ * Corresponding Author: Arash Gholoobi, Atherosclerosis Prevention Research Center, Mashhad University of Medical \\ Sciences, Mashhad, Iran.Email: Gholoobia@mums.ac.ir
}

\begin{tabular}{|c|c|}
\hline & Abstract \\
\hline $\begin{array}{l}\text { Received: } 30.05 .2017 \\
\text { Accepted: } 10.09 .2017\end{array}$ & \multirow[b]{2}{*}{$\begin{array}{l}\text { Background and Objective: Thrombolysis in myocardial infarction (TIMI) } \\
\text { frame count (TFC) is an objective and quantitative index of coronary flow, } \\
\text { and myocardial fractional flow reserve (FFR) is a lesion-specific index for } \\
\text { epicardial coronary stenosis. Currently, FFR is the most valid tool for } \\
\text { decision making in coronary interventions. However, it incurs relatively high } \\
\text { costs and it is not reimbursed by the insurance companies in Iran. In this } \\
\text { study, we aimed to determine the relationship between corrected TFC } \\
\text { (CTFC) and FFR in patients who are simultaneously undergoing coronary } \\
\text { angiography and FFR measurement for moderate coronary artery lesions. } \\
\text { Materials and Methods: This retrospective cross-sectional study was } \\
\text { performed on } 24 \text { patients (16 males and } 8 \text { females) with the mean age of } 57.7 \\
\text { years who underwent FFR for moderate coronary stenosis. Patients with } \\
\text { recent myocardial infarction, coronary ectasia, and slow flow coronary } \\
\text { syndrome were excluded. FFR was determined by measuring the mean } \\
\text { coronary pressure distal to the stenosis and comparison with the mean aortic } \\
\text { pressure using a pressure wire. On the other hand, the first frame used for } \\
\text { TFC was defined by a column of contrast extending across more than } 70 \% \\
\text { of the arterial lumen and the last frame count was one in which contrast first } \\
\text { appeared in the distal, pre-defined landmark branch for the coronary artery } \\
\text { of interest. CTFC was calculated for the left anterior descending (LAD) } \\
\text { coronary artery by dividing TFC of the LAD by a factor of } 1.7 \text {. } \\
\text { Results: Fifteen patients had LAD, seven had right coronary artery, and two } \\
\text { had left circumflex lesions. The mean values for CTFC and FFR were } 20.6 \\
\text { and } 0.90 \text {, respectively. There was not a statistically significant correlation } \\
\text { between FFR and CTFC (r=0.14; P=0.514). } \\
\text { Conclusion: Given that there is no significant correlation between CTFC and } \\
\text { FFR, CTFC cannot be used as an independent index for decision making in } \\
\text { coronary artery interventions. }\end{array}$} \\
\hline $\begin{array}{l}\text { How to Cite this Article: } \\
\text { Gholoobi A, Mohammadzadeh } \\
\text { Shabestari M, Jamshid Rezaei A, } \\
\text { Dabbagh VR. The Relationship } \\
\text { between Thrombolysis in } \\
\text { Myocardial Infarction Frame } \\
\text { Count and Fractional Flow } \\
\text { Reserve in Patients with Moderate } \\
\text { Coronary Stenosis Undergoing } \\
\text { Coronary Angiography. Sci J } \\
\text { Hamadan Univ Med Sci. 2017; } \\
\text { 24(3): 215-220. DOI: 10.18869/ } \\
\text { acadpub.ajcm.24.3.215. }\end{array}$ & \\
\hline & $\begin{array}{l}\text { Keywords: Angiography; Fractional Flow Reserve; Myocardial Infarction; } \\
\text { Thrombolysis }\end{array}$ \\
\hline
\end{tabular}


dof: 10.18869 /acadpub.ajcm.24.3.215

\title{
ارتباط (TIMI Frame Count (TFC با كسر ذخيره جريانى (FFR) در بيماران مبتلا به تنكى متوسط مروق كرونر كه تحت آنزيوكرافى كرونر قرار مى تَيرند
}

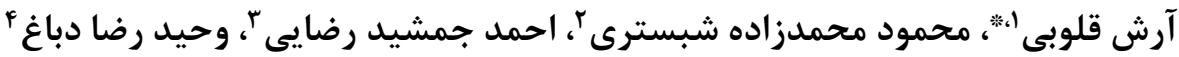

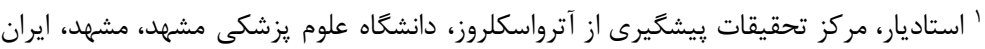

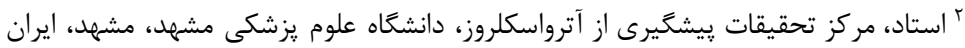

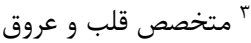

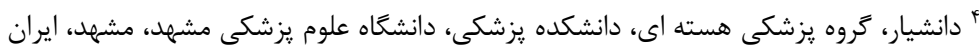
* نويسنده مسئول: آرش قلوبى، مركز تحقيقات بيشَيرى از آترواسكلروز، دانشكاه علوم يزشكى مشهد، مشهد، ايران.

ايميل:Mholoobia@mums.ac.ir

\begin{tabular}{|c|c|}
\hline קكيده & \\
\hline سابقه و هدف: تعداد فريم ترومبوليز در انفاركتوس ميو كارد (TFC) شاخصى عينى و كمى از جريان عروق & 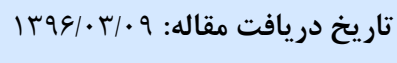 \\
\hline كرونر است و كسر ذخيره جريانى Fractional Flow Reserve; FFR) نيز يك شاخص براى تنغى & 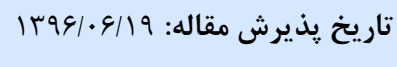 \\
\hline إيكارديال شريان كرونرى ناشى از يك ضايعه خاص مى باشد. امروزه FFR معتبرترين ابزار براى تصميم كَيرى & \\
\hline در مداخلات كرونرى مى باشد. با اين حال، هزينه آن نسبتا بالا است و توسط شركت هاى بيمه در كشور ما & تيزمكى همدان محفوظ نشر براى دانشكاه علوم \\
\hline يرداخت نمى شود. هدف از اين مطالعه تعيين ارتباط بين TFC الصلاح شده (CTFC) و FFR در بيمارانى & \\
\hline است كه همزمان تحت آنزيوَّرافى كرونر و اندازه گيرى FFR براى ضايعات عروق كرونر متوسط قرار مى كيرند. & \\
\hline مواد و روش ها: مطالعه كذشته نكر مقطعى حاضر شامل اطلاعات FF بيمار (19 مرد، و ^ زن با ميانكَين & \\
\hline سنى DV/V سال) بود كه براى تنكى عروق كرونرى متوسط خود تحت اندازه كيرى FFR قرار كرفتند. بيماران & \\
\hline مبتلا به سكته حاد قلبى اخير، اكتازى عروق كرونر و كندى جريان كرونر از مطالعه خارج شدند. FFR با & \\
\hline اندازه كيرى فشار متوسط كرونرى ديستال به تنكى نسبت به فشار متوسط آئورت به وسيله ى سيم فشارى & \\
\hline تعيين شد. همجنين در كليه بيماران محاسبه TFC با شمارش تعداد فريم هاى آنزيوكرافيكى كه بايد طى & \\
\hline شود تا ماده حاجب كه بيشتر از • درصد لومن شريانى را در فريم اول ير كرده است به لندمارك انتهايى & \\
\hline از پيش تعريف شده رى مربوطه برسد، انجام شد. در شريان نزولى قدامى رقم بدست آمده به عدد I/V & \\
\hline تقسيم شد. & \\
\hline يافتهها: يانزده بيمار داراى دركيرى در LAD، هفت بيمار RCA و دو بيمار LCX بودند. ميانكَين CTFC & \\
\hline 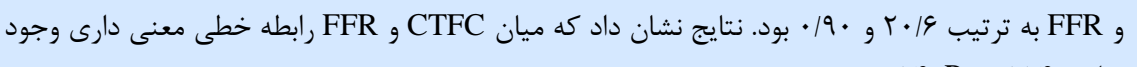 & \\
\hline 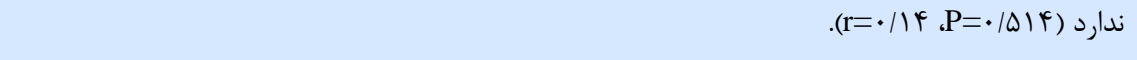 & \\
\hline نتيجهَيرى: با توجه به اينكه هيج ارتباط معنى دارى بين FFR و CFTC وجود ندارد، CTFC نمى تواند & \\
\hline به عنوان يك شاخص مستقل براى تصميم كيرى در مداخلات عروق كرونر استفاده شود. & \\
\hline ز زَان كليدى: آنزيوَرافى؛ انفار كتوس ميوكار & \\
\hline
\end{tabular}

مقدمه

آترواسكلروز را نشان ميدهد. به همين دليل، آنزيوكرافى عروق

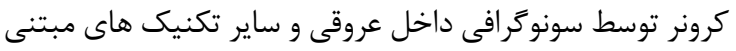
بر كاتتر و روشهاى غير تهاجمى تكميل مى شى شود.

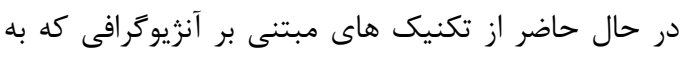

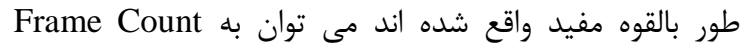
و (TIMI) Thrombolysis in myocardial infarction
بيمارى هاى عروق كرونر يكى از شايع ترين علل مرى و مير

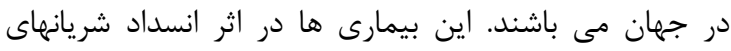

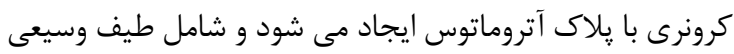

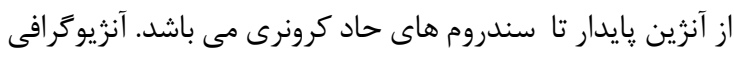

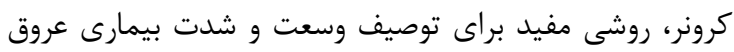

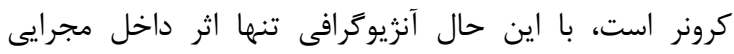


و تزريق به صورت دستى انجام شده بود (4-1 ميلى ليتر ماده

حاجب در هر بار تزريق).

اندازه كيرى فشار كرونر با استفاده از يك ئ سيم فشارى

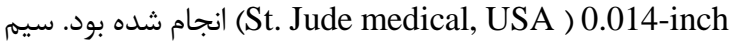

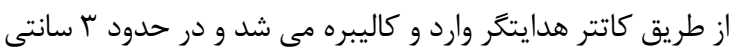
متر بعد از تنكى قرار مى كرفت. احتقان حداكثر با تجويز داخل

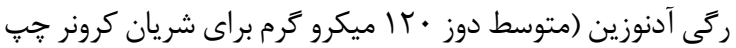

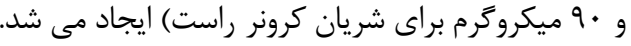

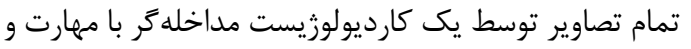
دانش كافى ارزيابى شد. كرونرها در نماى سرى و دمى داز از راست

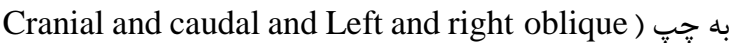
(angles بررسى شدند. نوع دستخاه آنزيوكرافى مورد استفاده Siemens Artis Zee تا آخرين سحَمان انتهايى آن انجام شد. لند مارك انتهايى براى شريان LAD محل دو شاخه شدن انتهايى و براى شريان سير

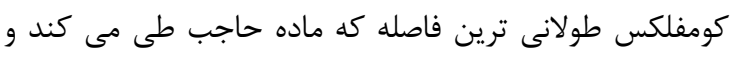
شامل ضايعه هدف مى باشد و براى شريان كرونر راست (RCA)

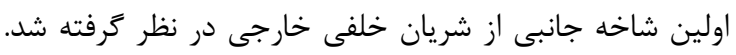

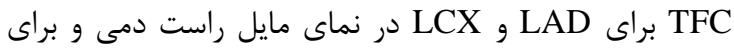
RCA در نماى مايل راست سرى ارزيابى شدند.

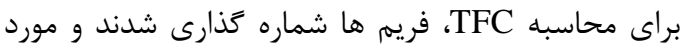

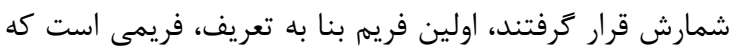

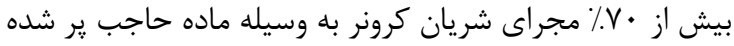

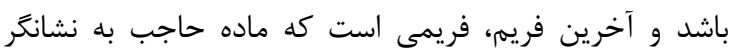

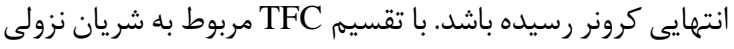

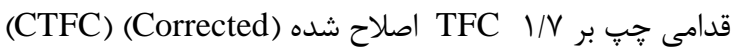
محاسبه مى شود. تجزيه و تحليل آمارى با استفاده از SPSS 17.0 انجام شد مداس.

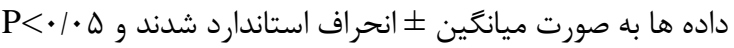

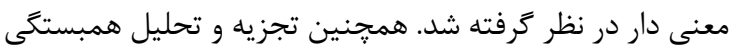
ييرسون به منظور بررسى روابط بين متغير ها انجام شد.

Lافته

در اين مطالعه يرونده YF بيمار مبتلا به بيمارى عروق كرونر

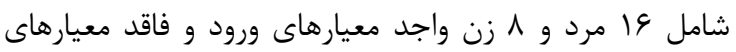

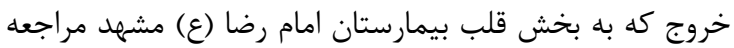

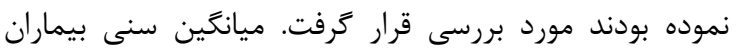

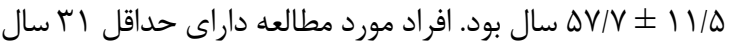
و حداكثر VA سال بودند. \& درصد بيماران سابقه مصرف سيخار، ^ نفر از بيماران داراى سابقه تشخيص يرفشارى خون، • ل بيمار

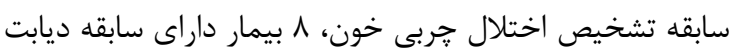

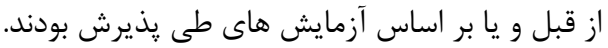

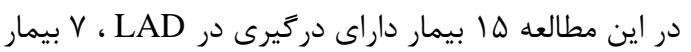

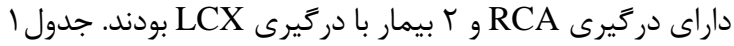

ارزيابى تهاجمى كسر ذخيره جريان كرونر ( Fractional Flow (Reserve= FFR

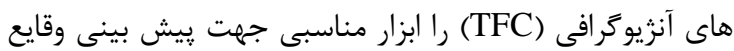

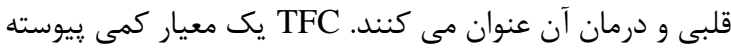

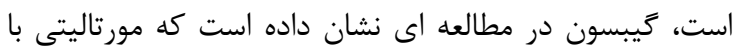

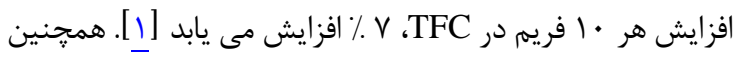

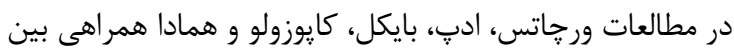

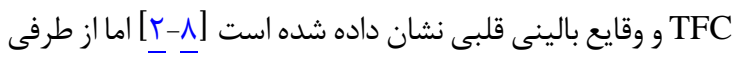
هم اكنون FFR دقيق ترين روش بررسى تنكى عروق كرونر مى دئي

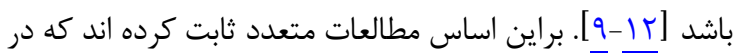

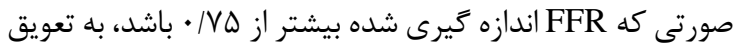

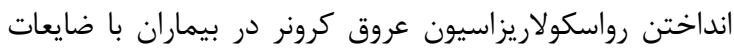
متوسط عروق كرونر مشكلى را براى بيمار ايجاد نخواهد

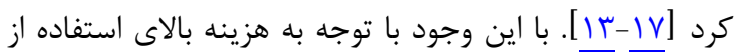
واير فشارى براى بيماران در مقايسه با آنزيوكرافى (براى محاسبه بـانه

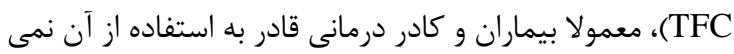

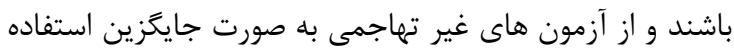

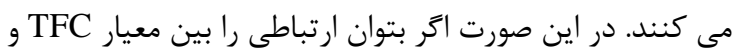

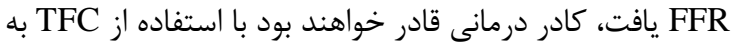

نتايج قابل مقايسه با FFR برسند

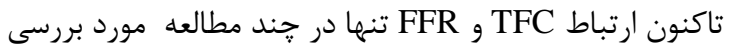

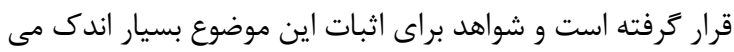

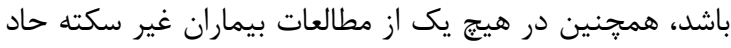

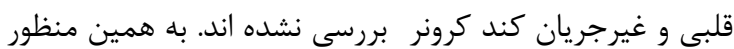

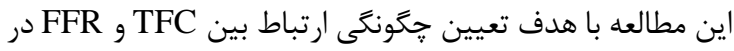
بيماران با تنگى متوسط عروق كرونر كه تحت آنزيوگر افيى كرونر

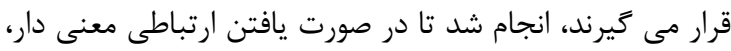

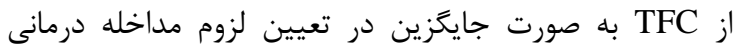

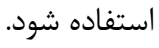

\section{مواد و روشها}

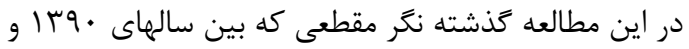

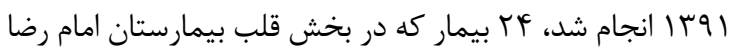

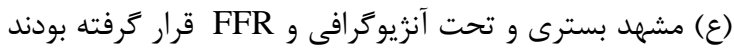

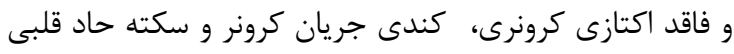

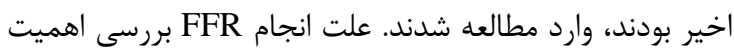

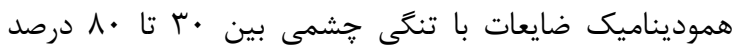

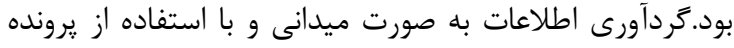

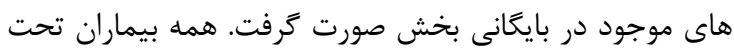

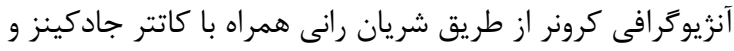

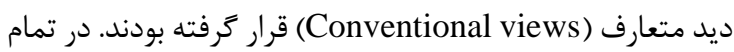
نمونه ها آنزيوكرافى توسط يك نفر انجام شده بود تا خطاى كار

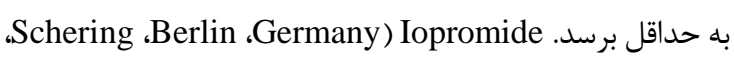
(Ultravist-370 به عنوان ماده حاجب مورد استفاده قرار گرفته 
جدول ا: شاخص هاى آنثيوگرافيك در بيماران مورد مطالعه بر حسب تمامى عروق

\begin{tabular}{|c|c|c|c|c|c|}
\hline انحراف از معيار & ميانگين & حداكثر & حداقل & 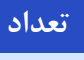 & متغير معيار \\
\hline$\cdot 1 \cdot r$ & .19 & $\cdot / 9$ & $\cdot 11$ & TY & (FFR) \\
\hline$\Lambda / \Gamma \Lambda$ & $r \cdot 19$ & f. & $N / T$ & TY & (TFC) \\
\hline$\| F / \Delta$ & $\Delta r / 9$ & $\wedge$. & r. & TF & شدت جشمى ضايعه (.)) \\
\hline
\end{tabular}

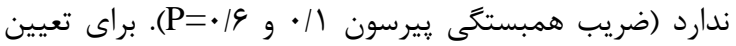

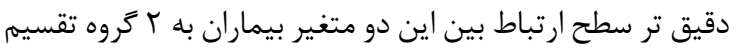

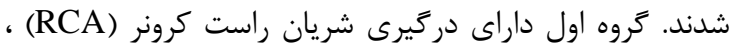

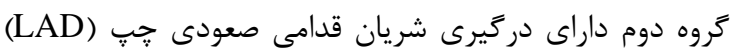

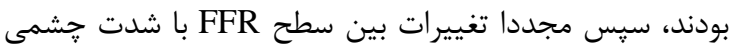

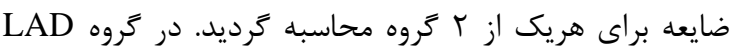

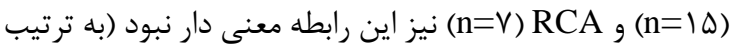

$$
\text { ضريب همبستخى پيرسون= T/ • و و / • •-). }
$$

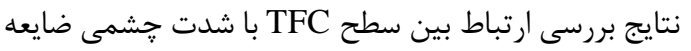

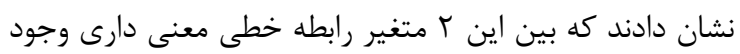

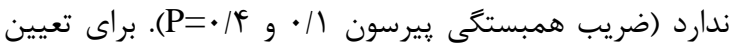

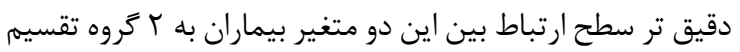

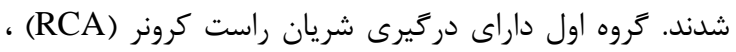

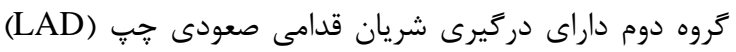
بودند، سيس مجددا تغييرات بين سطح FFR با TFC بر دراى

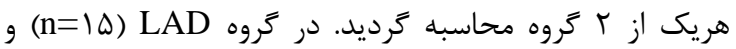

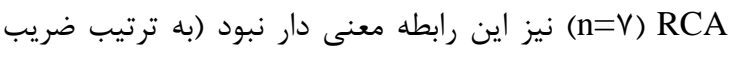

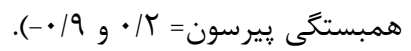

شاخص هاى آنزيوگرافيك در بيماران را بر حسب تمامى عروق

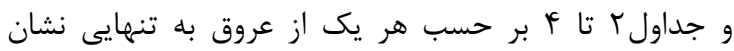
براى بررسى ارتباط بين FFR با TFC از آزمون همبستكى

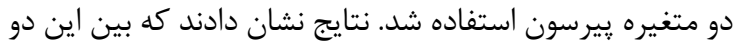

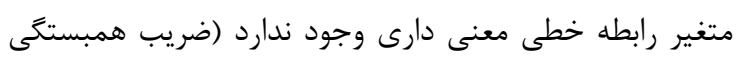

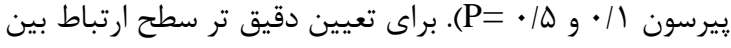

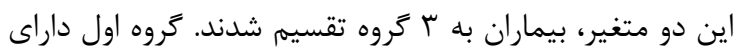

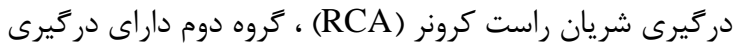

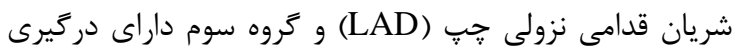
سيركومفلكس جٍ (LCX) بودند؛ سيس مجددا تغييرات بين

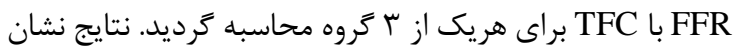

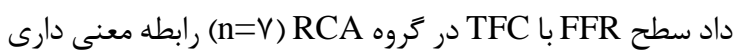

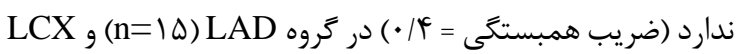
(n=r)

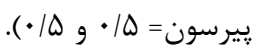

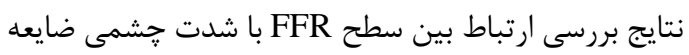

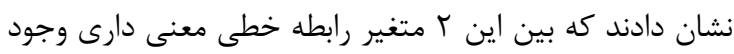

\begin{tabular}{|c|c|c|c|c|c|}
\hline انحراف از معيار & ميانكين & حداكثر & حداقل & ت تعداد & متغير معيار \\
\hline$\cdot 1 \cdot \mathrm{f}^{\mathrm{f}}$ & $\cdot 19$ & .19 & $\cdot 1 \Lambda$ & v & (FFR) \\
\hline $9 / 4$ & $r T / \Lambda$ & f. & 10 & v & (TFC) \\
\hline $\mid r / \Lambda$ & $\Delta T / \Lambda$ & $\wedge$. & f. & v & شدت جشمى ضايعه (./) \\
\hline
\end{tabular}

جدول Y: شاخص هاى آنزيوكرافيك در بيماران مورد مطالعه بر حسب RCA (شريان كرونرى راست)

\begin{tabular}{|c|c|c|c|c|c|}
\hline انحراف از معيار & ميانتين & حداكثر & حداقل & تعداد & متغير معيار \\
\hline$\cdot 1 \cdot 4$ & $\cdot 11$ & $\cdot 19$ & $\cdot 1 \mathrm{~A}$ & 10 & (FFR) \\
\hline$\Lambda / 1$ & $19 / 1$ & $r q / r$ & $\Lambda / T$ & 10 & $(\mathrm{TFC})$ \\
\hline $\mid F / T V$ & $0 \cdot 19$ & $\Lambda$. & r. & 10 & شدت جشمى ضايعه (./) \\
\hline
\end{tabular}

جدول بّ: شاخص هاى آنزيوگرافيك در بيماران مورد مطالعه بر حسب LAD (شريان نزولى قدامى جٍٍ)

\begin{tabular}{|c|c|c|c|c|c|}
\hline انحراف از معيار & ميانَين & حداكثر & حداقل & تعداد & متغير معيار \\
\hline$\cdot 1 \cdot 4$ & .19 & .19 & .19 & r & (FFR) \\
\hline$V / V$ & $T Y / D$ & r. & $19 / \cdot$ & r & (TFC) \\
\hline$|f /| f$ & $v \cdot / \cdot$ & $\Lambda$. & 4. & r & شدت جشمى ضايعه (./) \\
\hline
\end{tabular}

جدول fا: شاخص هاى آنزيوكرافيك در بيماران مورد مطالعه بر حسب LCX (شريان خرخشى جٍ)

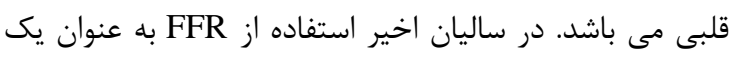

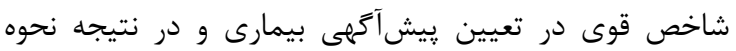

تصميم گيرى در مورد نحوه مداخلات درمانى براى بيماران

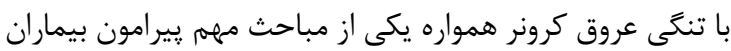


هيج كدام از ضايعات بين · · تا • م درصد اين گروه از بيماران از نظر هموديناميك مهلم نبودند و تحت آنزيويلاستى قرار نكرفتند.

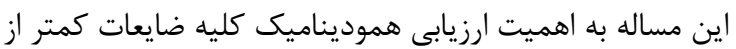

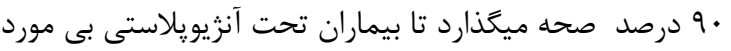
قرار نتيرند.

از آنجايى كه هدف اين مطالعه صرفا بررسى رابطه FFR و

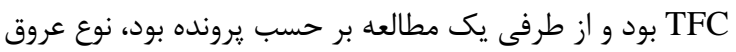

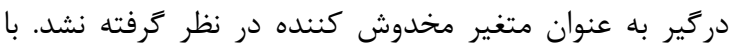

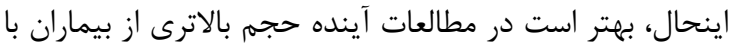

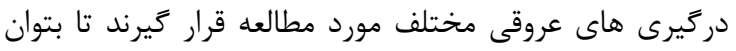
مقايسه خوبى از TFC در هريك از دسته هاى درو بيمارى داشته

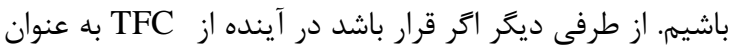

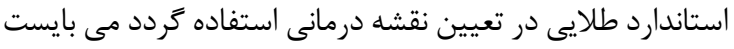

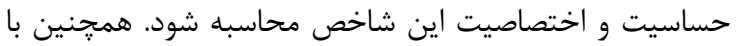
توجه به اينكه در اين مطالعه هيج كدام از بيماران داراى FFR كمتر از VD/ • نبودند امكان تعيين ارتباط بين FFR و

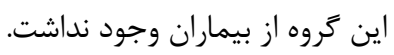

\section{نتيجه تيرى}

با توجه به اينكه هيج نوع همبستكى معنى دارى بين سطح

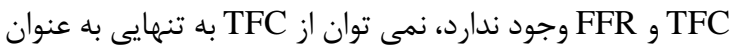

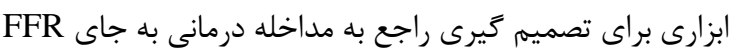

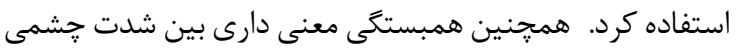
تنكى با TFC و FFR وجود ندارد.

\section{تشكر و قلروفاذى}

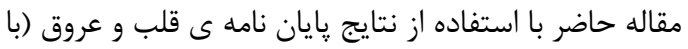

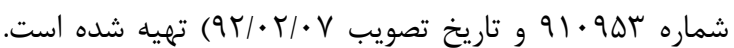

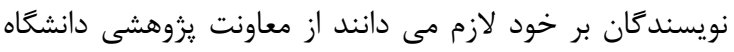

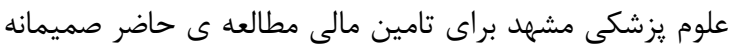

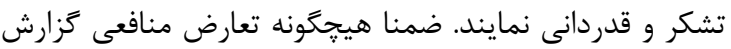
نغرديد.

\section{REFERENCES}

1. Gibson CM, Cannon CP, Daley WL, Dodge JT, Alexander B, Marble SJ, et al. TIMI frame count: a quantitative method of assessing coronary artery flow. Circulation. 1996;93(5):87988. PMID: 8598078

2. Vrachatis AD, Alpert MA, Georgulas VP, Nikas DJ, Petropoulou EN, Lazaros GI, et al. Comparative efficacy of primary angioplasty with stent implantation and thrombolysis in restoring basal coronary artery flow in acute ST segment elevation myocardial infarction: quantitative assessment using the corrected TIMI frame count. Angiology. 2001;52(3):161-6. PMID: 11269778 DOI: $10.1177 / 000331970105200301$

3. Schiller NB, Shah PM, Crawford M, DeMaria A, Devereux $\mathrm{R}$, Feigenbaum $\mathrm{H}$, et al. Recommendations for quantitation of the left ventricle by two-dimensional echocardiography. American Society of Echocardiography Committee on Standards, Subcommittee on Quantitation of TwoDimensional Echocardiograms. J Am Soc Echocardiogr. 1989;2(5):358-67. PMID: 2698218

4. Bickel C, Rupprecht HJ, Maimaitiming A, Welk I,
مداخلات درمانى مطرح شده است. با اين وجود تهاجمى بودن روش ارزيابى FFR از يك سو و از سوى ديخر هزينه بالاى استفاده

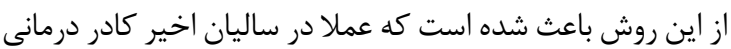

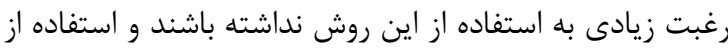

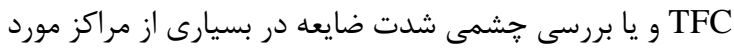

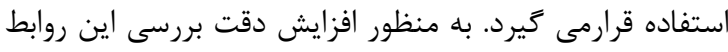

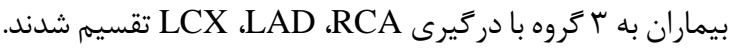
در كروه LCX به دليل اينكه تنها ب بيمار وجود داشت باد امكان بررسى همبستخى وجود نداشت اما در دو گروه ديگر نيز هيج

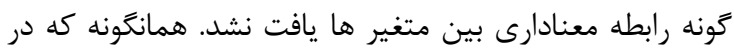

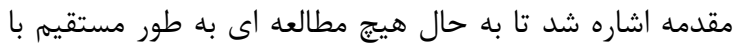

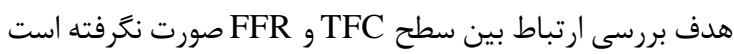

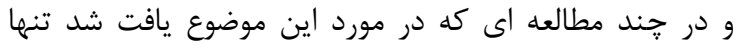

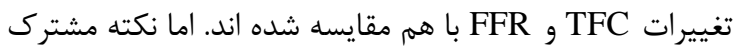
و قابل توجه در تمامى مطالعات صورت گرفته اين است كه

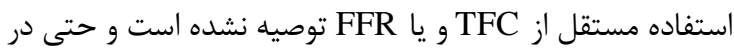
مطالعه ايسن و همكاران توصيه شده براى تعيين يرو گنوز بيماران

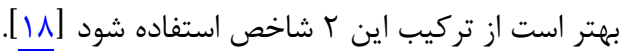

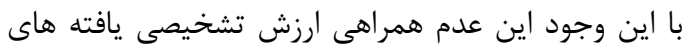

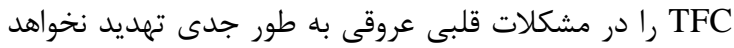

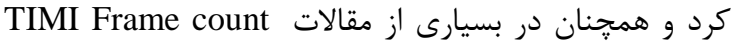

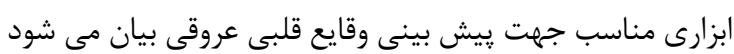

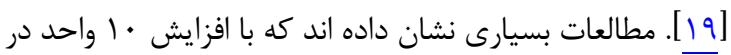

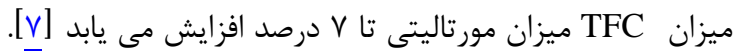

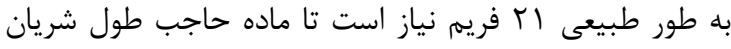
كرونرى را طى كند و عواملى جون طول شريان كرونرى، قدرت تزريق، قطر شريان، ضربان قلب، برون ده قلبى و هم راستا بودن

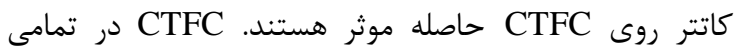

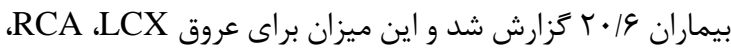

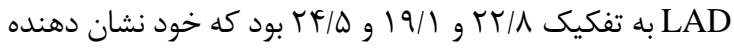
تاثير طول شريان كرونرى و قطر شريان بر روى تعداد فريم هاى

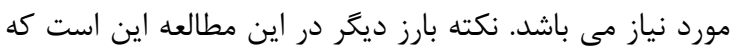

Blankenberg S, Krummenauer F, et al. The superiority of TIMI frame count in detecting coronary flow changes after coronary stenting compared to TIMI Flow Classification. $J$ Invasive Cardiol. 2002;14(10):590-6. PMID: 12368511

5. Hamada S, Nishiue T, Nakamura S, Sugiura T, Kamihata H, Miyoshi $\mathrm{H}$, et al. TIMI frame count immediately after primary coronary angioplasty as a predictor of functional recovery in patients with TIMI 3 reperfused acute myocardial infarction. J Am Coll Cardiol. 2001;38(3):666-71. PMID: 11527614

6. Edep ME, Guarneri EM, Teirstein PS, Phillips PS, Brown DL. Differences in TIMI frame count following successful reperfusion with stenting or percutaneous transluminal coronary angioplasty for acute myocardial infarction. Am J Cardiol. 1999;83(9):1326-9. PMID: 10235089

7. Gibson CM, Murphy SA, Rizzo MJ, Ryan KA, Marble SJ, McCabe $\mathrm{CH}$, et al. Relationship between TIMI frame count and clinical outcomes after thrombolytic administration. Thrombolysis In Myocardial Infarction (TIMI) Study Group. 
Circulation. 1999;99(15):1945-50. PMID: 10208996

8. Jespersen LL, Abildstrom SZ, Pena A, Hansen PR, Prescott E. Predictive value of the corrected Timi frame count in patients with stable angina pectoris symptoms but no obstructive coronary artery disease at angiography. Clin Res Cardiol. 2014;103(5):381-7. PMID: 24442337 DOI: 10.1007/s00392-014-0665-7

9. Pijls NH, De Bruyne B, Peels K, van Der Voort PH, Bonnier HJ, Bartunek J, et al. Measurement of fractional flow reserve to assess the functional severity of coronary-artery stenoses. $N$ Engl J Med. 1996;334(26):1703-8. PMID: 8637515 DOI: 10.1056/NEJM199606273342604

10. Kern MJ, Lerman A, Bech JW, De Bruyne B, Eeckhout E, Fearon WF, et al. Physiological assessment of coronary artery disease in the cardiac catheterization laboratory: a scientific statement from the American Heart Association Committee on Diagnostic and Interventional Cardiac Catheterization, Council on Clinical Cardiology. Circulation. 2006; 114(12):1321-41. PMID: 16940193 DOI: 10.1161/CIR CULATIONAHA.106.177276

11. Pijls NH, Van Gelder B, Van der Voort P, Peels K, Bracke FA, Bonnier HJ, et al. Fractional flow reserve. A useful index to evaluate the influence of an epicardial coronary stenosis on myocardial blood flow. Circulation. 1995;92(11):3183-93. PMID: 7586302

12. Tu S, Barbato E, Köszegi Z, Yang J, Sun Z, Holm NR, et al. Fractional flow reserve calculation from 3-dimensional quantitative coronary angiography and TIMI frame count: a fast computer model to quantify the functional significance of moderately obstructed coronary arteries. JACC Cardiovasc Interv. 2014;7(7):768-77. PMID: 25060020 DOI: 10.1016/j.jcin.2014.03.004

13. Rieber J, Jung P, Koenig A, Schiele T, Shapiro M, Hoffmann $\mathrm{U}$, et al. Five-year follow-up in patients after therapy stratification based on intracoronary pressure measurement. Am Heart J. 2007;153(3):403-9. PMID: 17307420 DOI: 10.1016/j.ahj.2006.11.013

14. Potvin JM, Rodés-Cabau J, Bertrand OF, Gleeton O, Nguyen $\mathrm{CN}$, Barbeau $\mathrm{G}$, et al. Usefulness of fractional flow reserve measurements to defer revascularization in patients with stable or unstable angina pectoris, non-ST-elevation and STelevation acute myocardial infarction, or atypical chest pain. Am J Cardiol. 2006;98(3):289-97. PMID: 16860011 DOI: 10.1016/j.amjcard.2006.02.032

15. Berger A, Botman KJ, MacCarthy PA, Wijns W, Bartunek J, Heyndrickx GR, et al. Long-term clinical outcome after fractional flow reserve-guided percutaneous coronary intervention in patients with multivessel disease. $J$ Am Coll Cardiol. 2005;46(3):438-42. PMID: 16053955 DOI: 10.1016/j.jacc.2005.04.041

16. Bech GJW, De Bruyne B, Pijls NH, de Muinck ED, Hoorntje JC, Escaned J, et al. Fractional flow reserve to determine the appropriateness of angioplasty in moderate coronary stenosis. Circulation. 2001;103(24):2928-34. PMID: 11413082

17. Tony H, Meng K, Wu B, Zeng Q. Among ectasia patients with coexisting coronary artery disease, TIMI frame count correlates with ectasia size and markis type IV is the commonest. Cardiol Res Pract. 2015;2015:282170. PMID: 25705544 DOI: $10.1155 / 2015 / 282170$

18. Esen AM, Acar G, Esen O, Emiroglu Y, Akcakoyun M, Pala $\mathrm{S}$, et al. The prognostic value of combined fractional flow reserve and TIMI frame count measurements in patients with stable angina pectoris and acute coronary syndrome. J Interv Cardiol. 2010;23(5):421-8. PMID: 20624205 DOI: 10.1111/j.1540-8183.2010.00579.x

19. TIMI Study Group. The thrombolysis in myocardial infarction (TIMI) trial. Phase I findings. N Engl J Med. 1985;312(14):9326. PMID: 4038784 DOI: 10.1056/NEJM198504043121437 